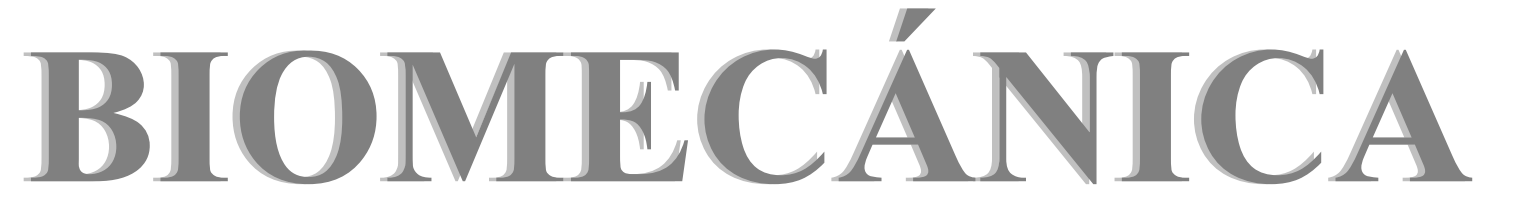

\title{
Tesis doctorales presentadas en España y Portugal en 2013 en el ámbito de la SIBB
}

En esta sección de la revista se listan las Tesis Doctorales presentadas en España y Portugal en el año 2013 y recogidas en la base de datos DART.

DART-Europe es una asociación de bibliotecas de investigación y de consorcios bibliotecarios que trabajan conjuntamente para la mejora del acceso global a las tesis doctorales europeas. DART-Europe facilita a los investigadores un único portal europeo para el acceso a tesis electrónicas (http://www.dart-europe.eu/). DART-Europe está apoyado por LIBER (Ligue des Bibliothèques Européennes de Recherche) y es el Grupo Europeo de Trabajo de la Networked Digital Library of Theses and Dissertations (NDLTD).

59 Área de Biomecánica y Medicina del Deporte

62 Área de Cirugía Ortopédica y Traumatología

64 Área de biomateriales 


\title{
Análisis de la influencia de la estimulación con vibraciones en la respuesta neuromuscular en competidores de esgrima
}

\author{
Autores \\ MERINO BOCOS, JUAN RAMÓN \\ Directores \\ ALFONSO JIMÉNEZ GUTIÉRREZ, ENRIQUE LÓPEZ ADÁN \\ Universidad Politécnica de Madrid \\ Fecha de lectura: 02 marzo 2012
}

\begin{abstract}
La esgrima es un deporte de combate en el que todas las acciones están dirigidas a conseguir el objetivo de la competición, que es el de tocar al contrario sin ser tocado, y para ello los tiradores/as se sirven de todas las herramientas, técnicas, tácticas y de condición física posibles a su alcance. La calidad de las acciones de los esgrimistas en competición dependerá fundamentalmente de dos de los sistemas involucrados en el proceso. Por un lado, la activación del sistema nervioso, y por otro lado la respuesta del sistema muscular. Una de las herramientas utilizadas en los últimos años para estimular el sistema neuromuscular, y que ha reportado en muchas investigaciones resultados positivos, ha sido la plataforma de vibraciones vertical. Por esto, decidimos llevar a cabo un estudio con deportistas de esgrima de competición con un protocolo de exposición aguda a las vibraciones, y medir el efecto producido por esta herramienta sobre el sistema neuromuscular a través del estudio de los cambios experimentados en los tiempos de reacción simple, tiempos de respuesta electiva y tiempos de movimiento, así como los efectos en la eficacia del tocado de esgrima analizados antes y después de recibir el estímulo vibratorio.

El estudio se desarrolló con tiradores/as de competición de nivel nacional y pertenecientes al Centro de Tecnificación de la Federación de Esgrima de Castilla y León (n=38; Edad: $22 \pm 9,08$ ). La muestra estaba compuesta por 12 mujeres y 26 hombres, de categorías, cadetes (13), júnior (12), y absolutos (13). El protocolo elegido fue realizado por cada participante en tres ocasiones, una inicial, otra tras pasar por una carga de estimulación en la plataforma de vibraciones, y una fase final, pasado un tiempo de recuperación de 10 minutos para comprobar el grado de disipación del efecto vibratorio. El estímulo elegido para la estimulación sobre la plataforma de vibraciones fue de una frecuencia de $50 \mathrm{~Hz}$, durante un periodo de 60 segundos y con una amplitud de $4 \mathrm{~mm}$. Los resultados se analizaron en función de las variables dependientes tiempo de reacción, tiempo de respuesta electiva, tiempo de movimiento, y precisión y eficacia. Estos datos se cruzaron con las variables independientes sexo, categoría, nivel deportivo y años de experiencia. El propósito del presente estudio fue el de analizar los efectos producidos por una intervención de estimulación neuromuscular mecánica en fase aguda en un grupo de tiradores/as de esgrima de competición.

Los resultados mostraron que la carga de estimulación neuromuscular mecánica (ENM) aplicada en nuestro estudio provocó un discreto efecto en la respuesta neuromuscular de los tiradores participantes en la investigación. Se encontraron efectos significativos provocados por el estímulo vibratorio en las siguientes variables: en el tiempo de reacción simple se registró una mejora del 8,1\%, en el tiempo de respuesta electiva a pie parado un $10 \%$, en la precisión a pie parado un $7 \%$, y en la eficacia a pie parado un $18,5 \%$. Igualmente se observaron ligeras diferencias por sexos, encontrando un efecto de mayor tamaño en el grupo femenino. Es necesario resaltar que las características particulares de la muestra parecen haber influido en los resultados encontrados de forma importante. Por último, debemos destacar que el efecto residual producido por la estimulación aplicada en nuestra investigación en algún caso superó los diez minutos, ya que se hallaron efectos positivos de la estimulación neuromuscular mecánica en varios de los registros finales como hemos visto.
\end{abstract}

Palabras clave: Deportes.

Registro 849013

Enlace de acceso: http://oa.upm.es/22101/1/JUAN_RAMON_MERINO_BOCOS.pdf 


\title{
El rendimiento académico de adolescentes de $2^{\circ}$ ciclo de ESO: Diferencias entre deportistas y no-deportistas
}

\author{
Autora \\ ANA CAPDEVILA SEDER \\ Director \\ CARLOS HERNANDO DOMINGO
}

Universitat Jaume I

El rendimiento académico durante la adolescencia es un tema que preocupa a docentes, padres, madres, investigadores, etc. Del mismo modo, un estilo de vida sedentario, propio de la sociedad moderna, está afectando cada vez más a la población infantil y adolescente, causando, entre otras, enfermedades y dolencias cardiorrespiratorias propias del adulto. Durante la adolescencia, el abandono deportivo se produce de forma masiva y la principal causa se centra en la falta de tiempo para compaginar deporte y estudios. Además, muchas investigaciones sugieren que el deporte y el rendimiento académico están relacionados de forma positiva.

En la presente Tesis se pretende analizar la influencia de ciertas variables personales, contextuales, de hábitos y deportivas sobre el rendimiento académico; así como examinar el rendimiento académico y ciertas variables de hábitos en busca de diferencias entre deportistas y no-deportistas. Un total de 313 adolescentes de $2^{\circ}$ ciclo de ESO participaron en el estudio, todos de centros de Castellón de la Plana, de los cuales 124 eran deportistas y 189 no-deportistas. A todos ellos se les administró el cuestionario CHTE sobre hábitos de estudio y el PFYTL sobre práctica física y tiempo libre. Además, se administró un cuestionario a los padres y se obtuvo las notas académicas de los sujetos.

Los principales resultados muestran que el perfil de sujeto con mejor rendimiento académico corresponde a las variables de género femenino, centro privado/concertado, nivel de estudios superior del padre y de la madre, mejores hábitos de estudio, menos ocio sedentario, sí practica deporte, sí compite, sí practica con entrenador/a, sus padres practican deporte. Además, de forma significativa, los sujetos deportistas tienen mejor rendimiento académico, mejores hábitos de estudio y dedican menos tiempo al ocio sedentario que los sujetos no-deportistas.

Palabras clave: Psicologia, Educació. Ensenyament. Formació. Temps lliure, Ensenyament primari i secundari, Esports, Didàctica de 1'Expressió Corporal.

Registro 769416

Enlace de acceso: http://hdl.handle.net/10803/119771

\section{Epidemiología y predictores psicológicos de la lesión en el deporte: un estudio sobre 25 modalidades deportivas}

\author{
Autora \\ CONSTANZA PUJALS \\ Directores \\ MARÍA OLIVA MÁRQUEZ, VÍCTOR J. RUBIO
}

Universidad Autónma de Madrid

Resumen no disponible

Palabras clave: Deportes, epidemología.

Registro 753729

Enlace de acceso: http://digitool-uam.greendata.es:1801/webclient/DeliveryManager?pid=62522\&custo m_att_2=simple_viewer 


\title{
Perfil nutricional en deportistas de un centro de tecnifica- ción. Implementación de un programa piloto de educación nutricional
}

\author{
Autora \\ SONIA MARTÍNEZ ANDREU \\ Directores \\ ANTONI AGUILÓ PONS, PERE TAULER RIERA \\ Universitat de les Illes Balears
}

\begin{abstract}
En cada etapa del ciclo vital es necesaria una ingesta que cubra los requerimientos basales y las necesidades propias debidas a la actividad física desarrollada. El crecimiento producido durante la adolescencia supone un incremento en la demanda energética, que debe ser cubierta para asegurar un desarrollo óptimo. El objetivo general es conocer el estado nutricional de los deportistas pertenecientes al centro de tecnificación de las Islas Baleares y determinar los efectos de un programa piloto de educación nutricional en el grupo de gimnasia artística.

Los resultados obtenidos revelan la existencia de una ingesta energética insuficiente en la población adolescente deportista. Por otra parte, en el grupo de gimnasia artística observamos una baja ingesta energética total con una distribución inadecuada de macronutrientes. El programa de educación nutricional mejora los niveles de conocimientos y de calidad alimentaria.
\end{abstract}

Palabras clave: Adolescencia, nutrición, deporte, antropometría, conocimientos.

Registro 748615

Enlace de acceso: http://hdl.handle.net/10803/112156 


\title{
Prótesis total de rodilla de revisión: análisis de sus indica- ciones, evolución, resultado clínico y la calidad de vida de sus pacientes
}

\author{
Autor \\ RAFAEL LUQUE PÉREZ \\ Directores \\ LUIS LÓPEZ-DURÁN STERN, FERNANDO MARCO MARTÍNEZ \\ Universidad Complutense de Madrid
}

\begin{abstract}
Durante los últimos años, el tratamiento de las enfermedades degenerativas de la rodilla se ha convertido en una de las patologías más habituales en los quirófanos de cirugía ortopédica. Dependiendo de la anatomía del paciente se pueden utilizar distintos tipos de implantes. Hay muchos tipos de artroplastias totales de rodilla (ATR). Se ha utilizado la Optetrak Condilar Constreñida (OCC), un tipo de artroplastia de revisión semi-constreñida para el tratamiento de la artrosis de rodilla grave y para la revisión de una artroplastia primaria desimplantada. Este estudio tuvo como objetivo evaluar y comparar la OCC implantada como procedimiento primario en casos de deformidades graves y como reemplazo de un implante primario desimplantado.

La supervivencia, los resultados clínicos y funcionales de la OCC como un implante primario o como una artroplastia de revisión son en general buenos o muy buenos. Las revisiones sépticas obtienen peores resultados clínicos y peores supervivencias que los demás grupos.

La calidad de vida de la mayoría de nuestros pacientes es buena-excelente. La mayoría de los pacientes están satisfechos con la mejoría obtenida con la cirugía debido a la diminución del dolor y al aumento de la movilidad.

La OCC es una muy buena opción para el tratamiento de la artrosis severa y para la revisión de una artroplastia de rodilla desimplantada.
\end{abstract}

Palabras clave: Cirugía.

Registro 840763

Enlace de acceso: $h$ ttp://eprints.ucm.es/23874/1/T34990.pdf 


\title{
Valoración de la actividad antimicrobiana en la profilaxis antibiótica en cirugía ortopédica. Influencia del manguito de isquemia
}

\author{
Autora \\ LAURA PRATS GISPERT \\ Directores \\ JOSÉ JUAN FERNÁNDEZ MARTÍNEZ, JOAQUIM ROS SALVADOR \\ Universitat de Lleida
}

\begin{abstract}
A pesar que la profilaxis antibiótica en nuestra práctica quirúrgica está totalmente aceptada, existen pocos trabajos que relacionen el efecto que puede ocasionar la aplicación del manguito de isquemia respecto la llegada del antibiótico profiláctico a los tejidos distales y como se mantiene durante toda la intervención. En esta tesis presentamos una investigación clínica observacional con el objeto de estudiar la concentración de cefonicid en tejido sinovial de la rodilla en una cohorte formada por 32 pacientes sometidos a una intervención de prótesis total de rodilla en las cuales se utiliza el manguito de isquemia; utilizando la cromatografía líquida de alta resolución como método de medida. Nuestros resultados muestran que si bien la concentración de antibiótico disminuye durante la intervención, ésta se mantiene en niveles superiores a la concentración mínima inhibitoria al final de la cirugía. En conclusión, podemos afirmar que la utilización del torniquete de isquemia en los procesos quirúrgicos, no interfiere en la acción del antibiótico profiláctico administrado para evitar la infección.
\end{abstract}

Palabras clave: Cirugía, ortopedia, oftalmologia, medicina.

Registro 808175

Enlace de acceso: http://hdl.handle.net/10803/123747 


\title{
Diseño y aplicaciones biomédicas de biomateriales funcio- nalizados basados en poliésteres de origen bacteriana
}

\author{
Autora \\ NINA DINJASKI \\ Directora \\ MARÍA AUXILIADORA PRIETO JIMÉNEZ \\ Universidad Complutense de Madrid
}

\begin{abstract}
En esta Tesis Doctoral mediante dos estrategias se obtuvo PHA con valor añadido: i) producción bacteriana de nano-partículas funcionalizadas in vivo; ii) síntesis del polímero funcionalizado. Mediante el uso de sistema BioF, basado en la N-terminal de fasina PhaF de Pseudomonas putida KT2442 que se une al gránulo y sirve como etiqueta de afinidad para anclar proteínas recombinantes, se inmovilizaron proteínas recombinantes al gránulo de PHA. Para obtención de mejor rendimiento de la proteína fusionada al gránulo de PHA, se estudio el proceso de unión de la etiqueta al gránulo y las funciones fisiológicas de las fasinas PhaF y PhaI, determinándose su función coordinada en la segregación de los gránulos durante la división celular y su uniforme distribución. Se identificaron dos funciones diferentes de los dominios C- y N-terminal de la fasina PhaF (C-terminal se une a ADN y realiza una función parecida a la de "histon-like" proteínas, mientras N-terminal es responsable de unión al gránulo). Se determinaron las condiciones óptimas para la producción de proteína recombinante fusionada al BioF y los factores imprescindibles para la formación de gránulos y síntesis de biomasa. Se ha concluido que la baja producción de la fasina PhaF junto con PhaI o BioF es crucial para obtención de mejor rendimiento de proteína recombinante. Además, se determinaron nuevas propiedades de PHACOS, PHA obtenido por fermentación que contienen grupos tioéster en la cadena lateral. Se demonstró su actividad antimicrobiana tanto frente la cepa tipo Staphylococcus aureus como las MRSA cepas de S. aureus. Se demonstró la disminución de la formación de biopeliculas de S. aureus en PHACOS comparado con PHO. Mediante el uso de una sonda fluorescente (H-ICG), se demostró tanto la biocompatibilidad de PHO y PHACOS como la actividad antimicrobiana de PHACOS in vivo en BALB/c ratones. Este resultado indica la posibilidad de uso de PHACOS para aplicaciones biomédicas.
\end{abstract}

Palabras clave: Biología molecular, bioquímica.

Registro 840772

Enlace de acceso: http://eprints.ucm.es/23884/1/T35014.pdf 


\title{
Los diagramas de equilibrio de fases MgO-ZnO-CaO-P2O5 y su aplicación al diseño y obtención de biomateriales basados en fosfato tricálcico
}

\author{
Autora \\ LETICIA MERCEDES CARBAJAL GALÁN \\ Directores \\ ÁNGEÑ CABALLERO CUESTA, MARÍA ANTONIA SAINZ TRIGO \\ Universidad Autónoma de Madrid
}

El propósito de la presente Tesis Doctoral ha sido establecer mediante estudios experimentales las compatibilidades en estado sólido y las relaciones de fusión del fosfato tricálcico en los sistemas ternario ZnO$\mathrm{CaO}-\mathrm{P} 2 \mathrm{O} 5$ y cuaternario $\mathrm{ZnO}-\mathrm{MgO}-\mathrm{CaO}-\mathrm{P} 2 \mathrm{O} 5$ y específicamente las regiones ricas en fosfato tricálcico en ambos sistemas y en óxido de cinc y fosfato tricálcico en el sistema ternario. Paralelamente se han revisado y establecido nuevas zona de los diagramas de equilibrio siguientes:

$\mathrm{Ca} 3(\mathrm{PO} 4) 2-\mathrm{Zn} 3(\mathrm{PO} 4) 2$,

$\mathrm{Ca} 3(\mathrm{PO} 4) 2-\mathrm{ZnO}$

$\mathrm{Ca} 3(\mathrm{PO} 4) 2-\mathrm{Zn} 3(\mathrm{PO} 4) 2-\mathrm{Mg} 3(\mathrm{PO} 4) 2$.

Estos estudios han permitido establecer los campos de estabilidad de $\alpha, \beta$ y $\alpha+\beta$ fosfato tricálcico dopado con cinc y magnesio en función de la temperatura y la composición así como los rangos de solución sólida de cinc y magnesio en fosfato tricálcico en función de la temperatura.

En segundo lugar y teniendo en cuenta la información obtenida en los estudios de los correspondientes diagramas de equilibrio de fases se diseñaron, formularon y obtuvieron biomateriales de $\alpha, \beta$ y $\alpha+\beta$ fosfato tricálcico modificados con óxido de cinc y con óxido de cinc/óxido de magnesio. Se estableció la influencia de estos elementos en estructura, transiciones de fase, sinterización, mineralogía y la microestructura de los materiales.

Posteriormente en muestras seleccionadas se realizó un estudio del comportamiento bioactivo "in vitro" en suero fisiológico artificial (SFA) y estudios de la citotoxicidad y

biocompatibilidad en cultivos primarios de osteoblastos humanos.

Finalmente se ha llevado a cabo un estudio preliminar para la obtención de materiales densos, con un escaso crecimiento cristalino, de fosfato tricálcico dopados con cinc y cinc/magnesio mediante la técnica de Spark Plasma Sintering (SPS)

El estudio persigue un objetivo de relevancia social que es la mejora de los patrones de salud y calidad de vida de las personas mediante la investigación y el desarrollo de materiales basados en fosfato tricálcico modificados con óxido de cinc y con óxido de cinc/óxido de magnesio de mineralogía y microestructura controlada con aplicación en biomedicina como sustituto y regenerador óseo.

Palabras clave: Material biomédico.

Registro 750141

Enlace de acceso: http://digitool-uam.greendata.es:1801/webclient/DeliveryManager?pid=61669\&custo m_att_2=simple_viewer 